\title{
A relação entre o conservadorismo contábil e os conflitos entre acionistas controladores e minoritários sobre as políticas de dividendos nas empresas brasileiras listadas na Bovespa ${ }^{*}$
}

\section{The relation between accounting conservatism and conflicts on dividend policies between major and minor shareholders of brazilian companies listed on Bovespa}

\author{
Rosimeire Pimentel Gonzaga \\ Professora do Departamento de Ciências Contábeis da Faculdade FUCAPE Business School • E-mail: ropgonzaga@gmail.com \\ Fábio Moraes da Costa \\ Professor do Departamento de Ciências Contábeis da Faculdade FUCAPE Business School • E-mail: fabio@fucape.br
}

Recebido em 10.1.1.2008 • Aceito em 20.05.2009 $\cdot 2^{a}$ versão aceita em 28.07.2009

\section{RESUMO}

O principal objetivo deste trabalho foi buiscar evidências empíricas quanto à relação do conservadorismo contábil com os conflitos sobre as políticas de dividendos entre acionistas minoritários e controladores nas companhias abertas listadas na Bovespa, compreendendo o período de 1995 a 2006 . Os dados foram coletados no software Economática. Para o teste das hipóteses, usou-se regressão com dados em painel utilizando como proxies para conservadorismo contábil a medida baseada em accruals utilizada por Givoly e Hayn (2000) e a baseada no book-to-market proposta por Beaver e Ryan (2000). Os resultados encontrados corroboram os achados por Ahmed et al. (2002), indicando que há relação entre o conservadorismo contábil e os conflitos sobre as políticas de dividendos entre acionistas nas empresas da amostra. Porém, não é possível afirmar sobre tal relação quando a métrica de conservadorismo baseada em book-to-market é utilizada.

Palavras-chaves: Conservadorismo. Conflitos. Políticas de Dividendos.

\section{ABSTRACT}

The main objective of this study was to present empirical evidence on the relation between accounting conservatism and conflicts about dividend policies between majority and minority shareholders of Brazilian publicly traded companies listed on BOVESPA. Data for the period from 1995 to 2006 was retrieved from Economatica. To test the hypotheses, panel data regression was used with two proxies for accounting conservatism - the accrual-based measure used by Givoly and Hayn (2000) and the book-to-marketbased measure proposed by Beaver and Ryan (2000). The results corroborate the findings by Ahmed et al. (2002), indicating a relation between accounting conservatism and conflicts about dividend policies between shareholders in the sample companies. The same cannot be affirmed, however, when the proxy based on bookto-market is employed.

Keywords: Conservatism. Conflicts. Dividend Politics.

* Artigo apresentado no $32^{\circ}$ ENANPAD, Rio de Janeiro-RJ, 2008. 


\section{INTRODUÇÃO}

O controle acionário das companhias brasileiras abertas é altamente concentrado ${ }^{1}$, sendo que poucos acionistas, geralmente, possuem o controle das ações com direito a voto (CARVALHAL-DA-SILVA; LEAL, 2005). Diante disso, surge um potencial conflito de interesses entre os que detêm ações ordinárias versus aqueles que possuem ações preferenciais (LEAL et al., 2002).

Segundo Silveira (2004), a atual estrutura de propriedade no Brasil geraria incentivos para a expropriação dos acionistas minoritários, pois os majoritários ou controladores obteriam o controle com uma participação menor do capital total, resultando em um dos principais conflitos de agência no país. $\mathrm{O}$ autor, também, ressalta que tal fato levou a uma série de iniciativas que foram tomadas para a proteção dos acionistas minoritários, tais como: alterações legais (Lei no 10.303/2001) e criação de níveis diferenciados de governança corporativa na Bovespa.

Um potencial conflito entre acionistas controladores e minoritários, nesse cenário, centra-se na política de distribuição de dividendos. O conflito pode surgir porque os acionistas controladores, que possuem direito a voto, nem sempre são os que detêm as ações preferenciais (LOPES; WALKER, 2008).

Assim, é possível remeter-se à Teoria da Agência para que se aborde a possibilidade de um agente assumir um comportamento oportunista, visando à maximização de sua utilidade individual e sacrificando os interesses do principal (MARTINEZ, 2001). Como o lucro líquido é a base para o cálculo dos dividendos, pode haver interesse do acionista controlador em realizar determinadas escolhas contábeis, baseado no pressuposto de que esse pode ter incentivos diferenciados dos outros fornecedores de capital (acionistas minoritários e credores) (WATTS, 2003a).
O conflito de agência pode ser visto como um elemento essencial dentro da visão contratual da firma desenvolvida por Coase (1937) e abordado por Jensen e Meckling (1976), ao estabelecerem que essa é constituída por um conjunto de relações (ou contratos) entre clientes, fornecedores, trabalhadores e executivos.

Um dos problemas em relação ao estabelecimento de contratos é o de que esses não são completos e nem perfeitos, pois existem contingências imprevisíveis (JENSEN; MECKLING, 1976; SILVEIRA et al., 2002).

A teoria da agência fornece estrutura para o papel da contabilidade enquanto fornecedora de informações: dado que os acionistas sempre estarão interessados nos resultados gerados pelos gestores, informações oferecidas por esses últimos sobre a organização aos acionistas reduzem a assimetria informacional e auxiliam na projeção de fluxos de caixa futuros e na formação de preços (LOPES; MARTINS, 2005).

Especificamente, sobre distribuição de lucros, informações com maior grau de verificabilidade poderiam reduzir o pagamento de dividendos excessivos, reduzindo possíveis conflitos sobre as políticas de dividendos, aumentando a confiança de atuais e potenciais investidores (AHMED et al., 2002).

Visando a primar pelo aumento da confiança das informações contábeis, essas são, geralmente, elaboradas com base no princípio contábil do conservadorismo, o qual pode ser definido como a tendência de se requerer um maior grau de verificabilidade para o reconhecimento de receitas e ativos se comparado ao grau de verificabilidade exigido para o reconhecimento de despesas e passivos (BASU, 1997; WATTS, 2003a).

Segundo Ahmed et al. (2002), os contratos podem incorporar o conservadorismo de duas formas: (i) os acionistas podem requerer 
o uso do conservadorismo contábil e (ii) os gestores podem utilizar o conservadorismo contábil para construir uma reputação conservadora dos relatórios financeiros.

Assim, o conservadorismo teria a função de proteção dos fornecedores de capital, sejam esses acionistas ou credores (WATTS, 2003a) e seu nível varia de acordo com o sistema legal no qual a empresa está inserida (BALL et al., 2000). As normas e práticas contábeis são distintas e aplicadas de formas diferenciadas entre os países, possuindo relação com as estruturas de governança das firmas e o ambiente de proteção legal aos investidores (LA PORTA et al., 1998; LOPES; MARTINS, 2005).

As características específicas de cada país podem agravar ou reduzir os conflitos. Assim, baseando-se nas características intrínsecas do mercado brasileiro, é possível estabelecer a seguinte questão de pesquisa:

\section{REFERENCIAL TEÓRICO}

\subsection{Conservadorismo Contábil}

Autores como Basu (1997) argumentam que a forma extrema de conservadorismo seria definida pela frase de Bliss (1924, p. 110): "Não antecipe nenhum lucro, mas antecipe todas as perdas" (BLISS, 1924, p.110).

Watts (2003a) apresenta quatro possíveis explicações para o surgimento do conservadorismo contábil. São elas: i) monitoramento de contratos (BEEKES; BROWN; CHIN, 2007; SMITH; WATTS, 1982; WATTS, 1977 e 1993); ii) probabilidade de ocorrência de litígios (KELLOG, 1984; LOBO; ZHOU, 2006); iii) impacto tributário (GUENTHER; MAYDEW; NUTTER, 1997; KIM; JUNG, 2007) e iv) consequências políticas para o organismo regulado (ZEFF, 1972).

Dentre as quatro possíveis explicações, a função contratual do conservadorismo é a mais usualmente utilizada e estudada empiricamente (AHMED; DUELLMAN, 2007; BASU, 1997; WATTS, 2003a e 2003b).
Há relação entre o conservadorismo contábil e os conflitos sobre as políticas de dividendos entre acionistas minoritários e controladores nas empresas brasileiras?

Baseando-se na literatura e sob o enfoque do conservadorismo contábil e sua função contratual $^{2}$, surge o objetivo de buscar evidências empíricas quanto à relação do conservadorismo contábil e os conflitos sobre as políticas de dividendos entre acionistas minoritários e controladores nas companhias abertas listadas na Bovespa.

Espera-se encontrar relação entre o conservadorismo contábil e os conflitos sobre as políticas de dividendos entre acionistas e, assim, contribuir para a discussão envolvendo a política de dividendos e o papel do conservadorismo nas informações contábeis divulgadas.

Watts (2003b) apresenta, ainda, um resumo de evidências empíricas quanto à existência do conservadorismo, bem como o seu aumento sobre o tempo e explicações alternativas.

Podem ser encontrados, na literatura, alguns trabalhos sobre o conservadorismo contábil e seus efeitos. Os Quadros 1 e 2 buscam listar os principais.

No Quadro $1 \bullet$, estão incluídos trabalhos empíricos internacionais sobre o conservadorismo contábil.

No quadro $2 \theta$, foram incluídos trabalhos acerca do conservadorismo contábil com foco no mercado brasileiro.

A literatura fornece uma distinção entre dois tipos de conservadorismo: de lucro e de balanço. O conservadorismo de lucros pode ser definido com base no reconhecimento assimétrico entre o grau de verificabilidade exigido por parte do reconhecimento de receitas em detrimento ao reconhecimento de

2 Para uma revisão sobre o tópico, sugere-se Watts (2003a). 
Quadro 1 Estudos anteriores internacionais e principais resultados

\begin{tabular}{|c|c|}
\hline Autor / Amostra & Metodologia / Resultados \\
\hline $\begin{array}{l}\text { Basu (1997) } \\
\text { que no período de } 1963 \text { a } 1990\end{array}$ & $\begin{array}{l}\text { Investigou o reconhecimento assimétrico de boas e más notícias. } \\
\text { Encontrou evidências de que os retornos refletem mais rapidamente as } \\
\text { más notícias em detrimento das boas notícias. }\end{array}$ \\
\hline $\begin{array}{l}\text { Pope e Walker (1999) } \\
\text { Empresas americanas listadas na Nyse/ } \\
\text { Lonex e empresas britânicas listadas na } \\
1976 \text { a } 1996\end{array}$ & $\begin{array}{l}\text { Discutiram as diferenças no timeliness e no conservadorismo entre } \\
\text { os Estados Unidos e o Reino Unido. Encontraram evidências de que } \\
\text { a contabilidade dos Estados Unidos é mais conservadora do que } \\
\text { contabilidade do Reino Unido quando comparando resultados antes } \\
\text { de itens extraordinários, e o oposto desse resultado foi encontrado } \\
\text { quando comparando resultados depois de itens extraordinários. }\end{array}$ \\
\hline $\begin{array}{l}\text { Ball, Kotari e Robin (2000) } \\
\text { Empresas de países classificados como } \\
\text { code-law e common-law no período de } \\
1985 \text { a } 1995\end{array}$ & $\begin{array}{l}\text { Analisaram as diferenças no timeliness e no conservadorismo contábil } \\
\text { entre países common law e code law. Confirmaram a hipótese de que } \\
\text { os resultados são menos oportunos e menos conservadores em países } \\
\text { code-law. }\end{array}$ \\
\hline $\begin{array}{l}\text { Givoly e Hayn (2000) } \\
\text { Todas as empresas da base Compustat no } \\
\text { período de } 1950 \text { a } 1998\end{array}$ & $\begin{array}{l}\text { Focaram os efeitos do conservadorismo nas ultimas décadas e en- } \\
\text { contraram evidências do aumento do conservadorismo ao longo do } \\
\text { tempo. }\end{array}$ \\
\hline $\begin{array}{l}\text { Beaver e Ryan (2000) } \\
\text { Todas as empresas da base Compustat no } \\
\text { período de } 1974 \text { a } 1993\end{array}$ & $\begin{array}{l}\text { Testaram a hipótese de que o book-to-market, medido pelas diferen- } \\
\text { ças entre o book-value e o market-value reflete o uso do conservado- } \\
\text { rismo contábil e encontraram que o book-value, é persistentemente } \\
\text { maior que o market-value, resultados atribuídos pelos autores aos } \\
\text { efeitos dos conservadorismo contábil e ambiente econômico. }\end{array}$ \\
\hline $\begin{array}{l}\text { Lubberink e Huijgen (2000) } \\
\text { Empresas amercianas no período de } 1995 \\
\text { a } 2004\end{array}$ & $\begin{array}{l}\text { Por meio da metodologia proposta por Basu (1997), observaram que } \\
\text { as preferências individuais dos gestores explicam o conservadorismo } \\
\text { contábil no resultado, sendo que os gestores mais avessos aos riscos } \\
\text { são mais conservadores se comparando aos menos avessos. A expli- } \\
\text { cação de tal fato segundo os autores é que, para reduzir a exposição } \\
\text { a fatos que possam diminuir a riqueza dos gestores, esses aumentam } \\
\text { o nível de conservadorismo no resultado, pelo fato de, em algumas } \\
\text { firmas, a riqueza do gestor ser atrelada ao seu desempenho. }\end{array}$ \\
\hline - Ball e Shivakumar (2005) & $\begin{array}{l}\text { Analisaram as diferenças no grau do conservadorismo entre empresas } \\
\text { britânicas abertas e fechado por meio de uma metodologia própria } \\
\text { baseada nos componentes transitórios dos lucros e apropriações } \\
\text { contábeis. Os autores encontraram que, em média, a qualidade dos } \\
\text { resultados é menor em empresas fechadas em detrimento das compa- } \\
\text { nhias fechadas. }\end{array}$ \\
\hline $\begin{array}{l}\text { Pae, Thornton e Walker (2005) } \\
\text { Todas as empresas da base COMPUSTAT } \\
\text { no período de } 1970 \text { a } 2001\end{array}$ & $\begin{array}{l}\text { Testaram as diferenças no conservadorismo no resultado por meio de } \\
\text { empresas com diferentes taxas de price-to-book. Os autores encontra- } \\
\text { ram evidências de que o conservadorismo incondicional, medido pela } \\
\text { taxa de price-to-book, é negativamente relacionado com o conser- } \\
\text { vadorismo condicional medido pela metodologia de Basu (1997), } \\
\text { sugerindo que pesquisas anteriores deveriam considerar a utilização } \\
\text { da taxa de price-to-book como variável de controle. }\end{array}$ \\
\hline $\begin{array}{l}\text { Roychowdhury e Watts (2005) } \\
\text { Todas as empresas da base COMPUSTAT } \\
\text { no período de } 1972 \text { a } 1999\end{array}$ & $\begin{array}{l}\text { Expandiram os resultados de Pae, Thornton e Welker (2005), demons- } \\
\text { trando que tais resultados são válidos apenas para períodos mais } \\
\text { curtos e que tendem a ser positivamente relacionados em períodos } \\
\text { mais longos. }\end{array}$ \\
\hline
\end{tabular}

despesas (WATTS, 2003a). Assim, o resultado contábil (lucro/prejuízo) é mais oportuno para reconhecer "más notícias" (retornos econômicos negativos da ação) do que "boas notícias" (retornos econômicos positivos da ação) (BASU, 1997).

Já a segunda forma de conservadorismo, a de balanço, é definida por Feltham e Ohl- 
Quadro 2 Estudos anteriores no mercado brasileiro e principais resultados

\begin{tabular}{|c|c|}
\hline Autor / Amostra & Metodologia / Resultados \\
\hline $\begin{array}{l}\text { Rangel e Teixeira (2003) } \\
\text { Economática de empresas do ramo de si- } \\
\text { derurgia e metalurgia no período de } 1998 \\
\text { a } 2001\end{array}$ & $\begin{array}{l}\text { Pesquisaram o uso do conservadorismo contábil pelas empresas } \\
\text { brasileiras como sendo um fator relevante para o mercado de capitais. } \\
\text { Os autores encontraram que, após expurgados os efeitos positivos dos } \\
\text { ativos, reserva de reavaliação e o ativo diferido, o valor do livro das } \\
\text { ações foi maior do que o valor de mercado das empresas da amostra. }\end{array}$ \\
\hline $\begin{array}{l}\text { Costa, Costa e Lopes (2005) } \\
\text { Cinco países da América Latina. No perío- } \\
\text { do de } 1995 \text { a } 2001\end{array}$ & $\begin{array}{l}\text { Investigaram por meio da metodologia desenvolvida por Basu (1997) } \\
\text { o uso do conservadorismo contábil em cinco países da América Latina } \\
\text { e encontraram que a contabilidade dos países da amostra não incor- } \\
\text { porava, significantemente, o retorno econômico. }\end{array}$ \\
\hline $\begin{array}{l}\text { Santos (2006) } \\
\text { Empresas brasileiras com ADRs negociadas } \\
\text { na Bolsa de Valores de Nova lorque, no } \\
\text { período de dezembro de } 1999 \text { a junho de } \\
2004\end{array}$ & $\begin{array}{l}\text { Observou o nível de utilização do conservadorismo nas demonstra- } \\
\text { ções contábeis em BR GAAP e US GAAP, utilizando a mensuração } \\
\text { desenvolvida por Basu (1997). O autor encontrou evidências de que } \\
\text { o uso do conservadorismo contábil não é maior nas demonstrações } \\
\text { contábeis em US GAAP para as empresas analisadas. }\end{array}$ \\
\hline $\begin{array}{l}\text { Antunes (2007) } \\
\text { Empresas brasileiras com níveis de gover- } \\
\text { nança diferenciados da BOVESPA - NDGB } \\
\text { no período de } 1996 \text { a } 2006\end{array}$ & $\begin{array}{l}\text { Observou as diferenças da qualidade das informações contábeis entre } \\
\text { as empresas brasileiras com níveis diferenciados de governança, } \\
\text { utilizando como proxy para a qualidade das informações contábeis o } \\
\text { conservadorismo, oportunidade e relevância. Os resultados encon- } \\
\text { trados indicam que a adesão aos níveis diferenciados de governança } \\
\text { corporativa não aumentou o uso do conservadorismo pelas empresas. }\end{array}$ \\
\hline $\begin{array}{l}\text { Coelho (2007) } \\
\text { Companhias brasileiras abertas e fechadas, } \\
\text { no período de } 1995 \text { a } 2004\end{array}$ & $\begin{array}{l}\text { Investigou por meio de regressões multivariadas, utilizando os } \\
\text { Modelos de Componentes Transitórios nos Lucros, de Apropriações } \\
\text { Contábeis e Fluxo de Caixa, de Apropriações Discricionárias e mo- } \\
\text { delos correlatados, se os resultados contábeis de empresas brasileiras } \\
\text { apresentam conservadorismo condicional. O autor encontrou evidên- } \\
\text { cias de que há uma ausência de conservadorismo condicional pelas } \\
\text { empresas brasileiras. }\end{array}$ \\
\hline $\begin{array}{l}\text { Mendonça (2008) } \\
\text { Empresas Brasileiras que emitiram ADRs } \\
\text { antes de } 2002\end{array}$ & $\begin{array}{l}\text { Analisou o impacto da Lei Sarbanes-Oxley (SOX) no conservadorismo } \\
\text { das demonstrações contábeis das empresas brasileiras que emitiram } \\
\text { ADRs antes de } 2002 \text {. Foram encontradas evidências de aumento } \\
\text { do conservadorismo para todas as empresas brasileiras, contudo, } \\
\text { observou-se um aumento do conservadorismo no Brasil a partir de } \\
\text { 2002, mas por outros motivos econômicos que não ocasionado pelo } \\
\text { efeito SOX. }\end{array}$ \\
\hline
\end{tabular}

son (1995) como a persistente subavaliação do valor contábil do capital dos acionistas em comparação com o valor de mercado da empresa.

O trabalho de Ahmed et al. (2002) apresenta evidências empíricas da relação entre conservadorismo e conflitos sobre políticas de dividendos, que é o foco do presente estudo. Os autores utilizaram dados de empresas americanas, as quais apresentam uma estrutura de controle acionário pulverizada, diferentemente do contexto brasileiro. Para a mensuração do conservadorismo, foram utilizadas duas proxies: book-to-market (BE-
AVER; RYAN, 2000) e uma medida baseada em accruals (GIVOLY; HAYN, 2000).

Ahmed et al. (2002) acrescentam, ainda, que firmas com conflitos mais severos sobre a política de dividendos tendem a fazer escolhas contábeis mais conservadoras. A explicação para tais resultados, segundo os autores, é a de que o conservadorismo contábil reduz resultados, diminuindo o pagamento dos dividendos.

\subsection{Política de dividendos e conflitos de agência}

A política de dividendos de uma empresa pode ser definida, basicamente, como a deci- 
são da empresa em reter o lucro visando ao reinvestimento na empresa ou distribuí-lo aos acionistas (ASSAF, 2003).

A teoria de agência sugere que há conflito de interesses sobre as políticas de dividendos (JENSEN; MECKLING, 1976). Uma possível explicação para tal fato é a de que o pagamento de dividendos pode transferir riqueza do gestor para o acionista (AHMED et al., 2002).

Alguns estudos científicos, tais como os de Modigliani e Miller (1961), Gordon e Lintner (1962) e Gordon (1963) foram desenvolvidos sobre as políticas de distribuição de dividendos e seu impacto no valor da firma, questionando sua relevância ou irrelevância, bem como sua influência no valor da empresa.

Miller e Modigliani (1961), com a teoria da irrelevância dos dividendos, argumentaram que o valor de uma empresa é determinado por lucros produzidos por seus ativos e não por como esses lucros são alocados entre dividendos ou lucros retidos.

Por outro lado, Gordon (1963) afirma que o valor de uma ação é função das expectativas de pagamento de dividendos futuros, baseando seu argumento na preferência dos acionistas em receberem dividendos em detrimento de possíveis ganhos futuros de capital. $\mathrm{O}$ autor encontrou evidências de relação entre política de dividendos e o valor de mercado da ação, em que uma mudança nas políticas de dividendos levaria a uma mudança no valor da ação.

Gordon (1963) e Lintner (1962) estabeleceram um dos principais argumentos que fundamentam a teoria da relevância dos dividendos: os autores afirmam que os investidores preferem dividendos correntes, ou seja, em situações de incerteza, os investidores são avessos ao risco, preferindo dividendos correntes a dividendos futuros e/ou ganhos de capital. Tal explicação passou a ser chamada de "Argumento do Pássaro na Mão".

Segundo a teoria da Sinalização, as alterações nas políticas de dividendos tendem a influenciar o valor das ações, sustentando tal afirmação na idéia de que, quando a distribuição de dividendos aumenta, o mercado tende a reagir positivamente. Por outro lado, uma redução, também, seria recebida como má notícia pelo mercado (LOSS; NETO, 2003).

Em relação aos conflitos de agência, a distribuição de dividendos pode reduzir o fluxo de caixa disponível para o gestor e tal fato reduziria sua liberdade para gerenciar resultados em benefício próprio (LIE, 2000). Nas empresas brasileiras há, ainda, uma tendência à retenção dos lucros em função da escassez de recursos no longo prazo (PROCIANOY, 1994). Em sentido contrário, os acionistas teriam preferência pela distribuição de dividendos (ALEN; BERNARDO; WELSH, 2000).

Diversos fatores influenciam as políticas de dividendos de uma firma. La Porta et al. (2000) afirmam que uma das respostas para as questões relativas à política de dividendos é de que essa está relacionada com os problemas de agência existentes entre gestores da firma e acionistas.

A regulação pode ser entendida como uma possível solução para a redução de tais conflitos. A legislação de um determinado país oferece aos investidores certos poderes para proteger seus investimentos das ações dos gestores e essas normatizações são diferentes entre países, em função das características legais existentes (LA PORTA et al., 2000).

Com base nas características de cada país, é possível estabelecer sua divisão em dois blocos: países common-law e países code-law. Países que fizeram parte do Império Britânico, geralmente, são classificados como common-law, tendo suas normas e regulamentações ligadas aos costumes e tradições. Por outro lado, os países que tiveram influência do Império Romano e Francês, geralmente, são classificados como code-law, nos quais a origem das regulamentações está ligada ao texto: para que algo tenha valor é necessário que esteja explícito no texto legal (LOPES; MARTINS, 2005). 
Nos países em que há grande concentração de propriedade das ações, como aqueles baseados no modelo code-law, existe uma menor proteção aos acionistas, enquanto em países baseados no modelo common-law - nos quais há baixa concentração de propriedade das ações - oferecem uma melhor proteção legal aos acionistas (LA PORTA et al., 1998).

Os reguladores brasileiros, visando a melhorar a proteção legal aos acionistas minoritários, estabeleceram um dividendo mínimo obrigatório por meio da Lei 10.303/2001.

\section{DESENVOLVIMENTO DE HIPÓTESES}

No Brasil, os acionistas controladores podem combinar de diversas formas sua participação acionária nas empresas. Se a empresa possuir, apenas, ações ordinárias, o acionista controlador apresentará maior participação no total de votos; já empresas que possuem capital formado por ações ordinárias e preferenciais, o acionista controlador poderá optar por exercer o controle por meio da posição majoritária no total de votos ou, além de uma posição majoritária no total de votos, exercer participação nos direitos de fluxo de caixa (SARLO NETO, 2004).

Ademais, existem evidências de que, no Brasil, o principal conflito não ocorre entre acionistas e gestores como em outros mercados e, sim, entre acionistas controladores e minoritários ${ }^{3}$ (LOPES; WALKER, 2008). Tal fato ocorre em função da concentração acionária existente e do ambiente institucional mais fraco (ANDERSON, 1999), diferentemente de países com mercados de capitais mais desenvolvidos, como Estados Unidos e Inglaterra (AHMED et al., 2002). Nesse contexto, a emissão de ações preferenciais pelas empresas no Brasil, possibilita a manutenção do controle oferecendo pequenas participações na estrutura de propriedade e propicia a participação de um grupo de acionistas minoritários com direitos distintos dos possuídos pelos acionistas controladores, aumentando a possibilidade de ocorrência de conflitos (SARLO NETO, 2009).

Ainda, em função da existência da distinção entre as ações ordinárias que possuem direito a voto e as ações preferenciais que não possuem direito a voto, os acionistas detentores das ações ordinárias, uma vez que não possuem direito preferencial dos dividendos, podem não ter interesse em pagar dividendos, visto que esses podem transferir suas riquezas para os acionistas minoritários que não possuem direito a voto, mas recebem dividendos, ao menos os obrigatórios por lei (AHMED et al., 2002; ANDERSON, 1999; LOPES; WALKER, 2008).

Como resultado, mecanismos são implementados nas companhias visando a mitigar tais conflitos e uma das formas seria o aumento do grau de conservadorismo contábil (AHMED et al., 2002). Quando os problemas de agência entre acionistas controladores e minoritários são mais severos, haveria um aumento ainda maior do grau de conservadorismo (ROYCHOWDHURY; WATTS, 2007).

$\mathrm{O}$ alinhamento de interesses entre acionistas controladores e minoritários implicaria na redução de problemas de agências entre as partes sendo que os graus de alinhamento dos interesses desses resultariam na variação na demanda por conservadorismo entre as firmas (BERLE; MEANS, 1932; JENSEN; MECKLING, 1976; ROYCHOWDHURY; WATTS, 2006).

Watts (2003) sustenta que o conservadorismo contábil reduz a probabilidade dos valores dos ativos ou lucros estarem superestimados, diminuindo a probabilidade de ocorrência de distribuição de resultados, que violem os contratos ou que possam impactar

\footnotetext{
Conflitos entre acionistas e gestores são considerados conflitos de agência tipo I; conflitos entre acionistas majoritários e minoritários são considerados conflitos de
} agência tipo II. 
o valor da firma. Isso poderia gerar conflitos entre acionistas minoritários e controladores.

Se, por um lado, os conflitos de interesse podem ser gerados em função dos acionistas controladores não possuírem direito preferencial sobre os dividendos e, portanto, optarem por reduzir os pagamentos de dividendos, por outro lado, os acionistas minoritários podem preferir o aumento dos dividendos para maximizar a utilidade (LEAL et al., 2002).

Nesse contexto, informações contábeis mais conservadoras podem reduzir os pagamentos de dividendos excessivos, exercendo o papel de mecanismo redutor desses confli- tos, mediante o alinhamento de interesses do acionistas (AHAMED et al., 2002).

Assim, para que se verifique se tal relação existe, a seguinte hipótese será testada empiricamente:

$\mathrm{H}_{0}$ : Não há relação entre o conservadorismo contábil e os conflitos sobre as políticas de dividendos entre acionistas minoritários e controladores nas companhias abertas brasileiras.

Espera-se encontrar evidências que corroborem estudos anteriores, em que foram encontrados indícios de relação entre conservadorismo contábil com os conflitos sobre políticas de dividendos.

\section{METODOLOGIA}

O objetivo deste trabalho consiste na busca de evidências empíricas quanto à relação do conservadorismo contábil e os conflitos entre acionistas minoritários e controladores sobre as políticas de dividendos nas empresas brasileiras.

Para que fosse possível testar a hipótese apresentada anteriormente, foram utilizados os modelos propostos por Ahmed et al. (2002).

A amostra foi coletada pelo software Economática e os dados das companhias abertas listadas na Bolsa de Valores de São Paulo (Bovespa) foram coletados compreendendo o período entre 1995 e 2006. Foi utilizada a técnica de dados em painel com efeitos fixos, após ser aplicado o teste de Hausman para cada equação.

\subsection{Proxies para Conflitos sobre as Políticas de Dividendos}

Foram utilizadas quatro proxies para conflitos sobre as políticas de dividendos entre acionistas minoritários e controladores: incerteza operacional (SROA) medido pelo desvio-padrão do ROA - retorno sobre o ativo, nível de dividendos (DIV), nível de endividamento (END) e proporção do direito de voto (voting rights) em relação ao direito a fluxo de caixa (cash flow right) do maior acionista (IND ON/PN).

Firmas com maiores graus de incerteza operacional (SROA) quanto a lucros futuros apresentam maior risco, pois os gestores irão requerer maior conservadorismo para reduzir a probabilidade de pagamentos excessivos de dividendos e, dessa forma, podem apresentar maiores conflitos. Assim, espera-se que quanto maior a incerteza operacional maior a probabilidade de ocorrência de conflitos entre acionistas sobre as políticas de dividendos e utilização do conservadorismo contábil (AHMED et al., 2002; WATTS, 1993).

A segunda proxy para conflito, o nível de dividendos pagos (DIV), é baseada na argumentação de que gestores de firmas que pagam maiores dividendos tendem a fazer escolhas contábeis mais conservadoras para evitar a distribuição excessiva de recursos, o que aumentaria o risco inerente à firma e, consequentemente, os conflitos demandando a aplicação do conservadorismo contábil (AHMED et al., 2002).

O grau de endividamento (END) teria relação com os conflitos sobre as políticas de dividendos porque um maior endividamento 
implicaria maiores obrigações, comprometendo o desempenho da firma e diminuindo os dividendos futuros. Assim, firmas com maiores graus de endividamento deveriam apresentar uma contabilidade mais conservadora (AHMED et al., 2002).

O grau de concentração acionária pode influenciar os conflitos inerentes às políticas de dividendos. $\mathrm{O}$ acionista controlador, ou seja, com a maior quantidade de ações ordinárias (voting right) e com uma quantidade menos significativa de ações preferenciais (cashflow right) teria menor interesse na distribuição de dividendos (LOPES; WALKER, 2008). Firmas com maior concentração acionária oferecem maiores oportunidades para expropriação dos acionistas minoritários pelos acionistas controladores, o que supõe que firmas com maior concentração das ações com voting right têm menores pagamentos de dividendos, pois o controlador optará por pagar menores dividendos, podendo expropriar os acionistas minoritários (CARVALHAL-DA-SILVA; LEAL, 2005).

Por outro lado, firmas com maiores concentrações das ações com cash flow right têm um maior alinhamento de interesse entre controladores e acionistas minoritários, mediante maiores pagamentos de dividendos, o que poderia levar as firmas com maiores concentrações de cash flow right a pagarem maiores dividendos (CARVALHAL-DA-SILVA; LEAL, 2005).

Utilizaram-se as seguintes variáveis de controle: ROA: controle por rentabilidade e LOGATIVO: controle por tamanho, pois, dado os altos custos do conservadorismo, firmas mais lucrativas e maiores podem dispor de escolhas mais conservadoras (WATTS; ZIMMERMAN, 1978). Além disso, foi utilizada a variável de controle REAV: controle por crescimento das vendas, porque o conservadorismo, geralmente, é afetado pelo crescimento de oportunidades, que, também, afeta os accruals e que pode influenciar o valor de mercado das ações: book-to-market
(AHMED et al., 2002; DECHOW; SLOAN, 1997; PENMAN; ZHANG, 2002).

\subsection{Proxy baseada no book-to-market}

Essa proxy para mensurar conservadorismo contábil visa a refletir o efeito do conservadorismo no valor patrimonial da ação.

Beaver e Ryan (2000) distinguem duas fontes de variação no book-to-market: viés e lag no reconhecimento contábil. Eles encontraram evidências empíricas de que o book-tomarket é correlacionado com futuros retornos das ações. Pelo viés no reconhecimento contábil, os autores argumentam que o patrimônio líquido é, persistentemente, menor do que o valor de mercado. Assim, o market-to-book é, persistentemente, acima de 1 e, pelo lag no reconhecimento contábil, eles encontraram o reconhecimento no book-value de ganhos e perdas inesperadas que foram reconhecidos no decorrer do tempo em vez de imediatamente. Como resultado, o book-to-market é, temporariamente, menor nos anos da amostra do que o valor da média do período, encontrando que o componente do viés específico de cada firma é associado com o conservadorismo contábil (BEAVER; RYAN, 2000).

Beaver e Ryan (2000) mensuram o viés (conservadorismo) específico de cada firma e o lag pela regressão do book-to-market atual com lag dos retornos das firmas por meio de dados em painel com efeitos fixos para cada firma. O efeito fixo da firma visa a capturar a variação temporal para reconhecimento de ganhos e perdas no book-value (AHMED et al., 2002).

Baseando-se na metodologia desenvolvida por Beaver e Ryan (2000), a proxy baseada no coeficiente do efeito fixo específico para cada firma, $a_{i}$, é derivada do seguinte modelo:

$$
B T M_{i, t}=\alpha+\alpha_{i}+\alpha_{t}+\Sigma_{k=6} \beta_{k} R E T_{i, t-k}+\mathrm{e}
$$

em que:

BTM $_{\mathrm{i}, \mathrm{t}=}$ o book-to-market da firma I, no período t; 
$\mathrm{a}_{\mathrm{i}}=\mathrm{o}$ viés no reconhecimento específico de cada firma no book-to-market;

$\mathrm{a}_{\mathrm{t}}=\mathrm{o}$ viés no reconhecimento específico do tempo no book-to-market de todas as firmas; $\operatorname{RET}_{\mathrm{i}, \mathrm{t}}=$ Retorno da ação da firma i, no período $t$.

O coeficiente $a_{i}$ representa o viés no reconhecimento contábil específico para cada firma, sendo essa a medida utilizada para conservadorismo contábil no presente trabalho.

\subsection{Proxy baseada em accruals}

A proxy desenvolvida por Givoly e Hayn (2000) visa a refletir o conservadorismo por meio do grau de persistência de accruals negativos (AHMED et al., 2002).

Givoly e Hayn (2000) argumentam que o conservadorismo contábil leva a accruals persistentemente negativos e que as mudanças nos resultados, fluxos de caixa e accruals no decorrer do tempo estão associadas ao conservadorismo.

Os accruals, antes da depreciação, foram utilizados como proxy para o conservadorismo contábil, aplicando-se a mesma metodologia empregada por Ahmed et al. (2002).

Para cálculo dos accruals foi utilizada a seguinte metodologia de cálculo:

$A C C_{i, t}=F C O_{i, t}{ }^{4}-L L_{i, t}$

$\mathrm{FCO}_{\mathrm{i}, \mathrm{t}}=$ Fluxo de caixa operacional da firma i, no período t;

$\mathrm{LL}_{\mathrm{i}, \mathrm{t}}=$ Lucro líquido da firma i, no período $\mathrm{t}$.

Para evitar distorções, os accruals foram deflacionados pelo total do ativo do período anterior ( $\mathrm{t}-1)$.

\section{RESULTADOS E DISCUSSÕES}

Nessa seção, serão descritos e comentados os resultados encontrados nas regressões de cada modelo utilizado.

A Equação 1 foi utilizada para verificar a relação do conservadorismo contábil e os conflitos entre acionistas minoritários e controladores sobre as políticas de dividendos utilizando-se como proxies para conservadorismo contábil as medidas baseadas no bookto-market (BEAVER; RYAN, 2000) e a accruals (GIVOLY; HAYN, 2000) como segue:

Equação 1 - Conservadorismo e conflitos sobre as políticas de dividendos

$$
\begin{aligned}
& C O N=\beta_{1}+\beta_{2} S R O A+\beta_{3} I N D O N / P N+ \\
& \beta_{4} D I V+\beta_{5} E N D+\beta_{6} L O G A T I V O+ \\
& \beta_{7} R E A V+\mathrm{e}
\end{aligned}
$$

em que:

BTM: Proxy para conservadorismo contábil: medida baseada no book-to-market;
ACC: Proxy para conservadorismo contábil: medida baseada em accruals;

SROA: Proxy para conflito por meio da incerteza operacional: desvio-padrão do ROA;

IND ON/PN: Proxy para conflitos: ações ordinárias do maior acionista em razão do somatório dos percentuais de ações ordinárias e preferenciais desse mesmo acionista;

DIV: Percentual de dividendos distribuído pela firma no período;

END: Grau de endividamento médio do período: dívida total em razão do total de ativos; ROA: Controle por rentabilidade;

LOGATIVO: Controle de tamanho, logaritmo do total de ativos;

REAV: Controle por crescimento das vendas: retorno anual sobre as vendas.

A Tabela $1 \oslash$ apresenta os resultados para a Equação 1 - A relação do conservadorismo contábil com conflitos sobre as políticas de

4 Fluxo de Caixa Operacional = Lucro Operacional + Outras Receitas e/ou Despesas Operacionais - Variação do Ativo Circulante - Variação do Passivo Circulante Variação das Disponibilidades + Variação do Financiamento a Curto Prazo + Depreciação e/ou Amortização. Adaptado de Souza (2006). 
Tabela 1 Estatística de Regressão em Painel - Efeito Fixo

Proxy para Conservadorismo Baseada em Accruals $\times$ Conflitos $A C C=\beta_{1}+\beta_{2} S R O A_{i, t}+\beta_{3} I N D_{-} O N / P N_{i, t}+\beta_{4} D I V_{i, t}+\beta_{5} E N D_{i, t}+\beta_{6} L O G A T I V O_{i, t}+\beta_{7} R E A V_{i, t}+\varepsilon$

\begin{tabular}{l|c|c|c|c}
\hline ACC & Sinal Esperado & Coeficientes & Estatística $-\mathbf{t}$ & $\boldsymbol{P}$-value \\
\hline$\beta_{2}$ SROA & + & 0,513 & 4,26 & $0,000^{* * *}$ \\
\hline$\beta_{3}$ IND ON/PN & + & 0,015 & 0,23 & 0,821 \\
\hline$\beta_{4}$ DIV & + & $-0,001$ & $-2,07$ & $0,039^{* *}$ \\
\hline$\beta_{5}$ END & + & $-0,049$ & $-4,24$ & $0,000^{* * *}$ \\
\hline$\beta_{6}$ LOGATIVO & + & 0,111 & 5,20 & $0,000^{* * *}$ \\
\hline$\beta_{7}$ REAV & + & 0,000 & 5,04 & $0,000^{* * *}$ \\
\hline$\beta_{1}$ & & $-1,870$ & $-6,08$ & 0,000 \\
\hline$R^{2}$ ajustado & & & & 0,4162 \\
\hline$N^{\circ}$ Observações & & & & 1894 \\
\hline Prob $>$ F & & & & 0,000 \\
\hline
\end{tabular}

em que: ${ }^{*}, * *, * *$ Estatisticamente significantes ao nível de $1 \%, 5 \%$ e $10 \%$ respectivamente;

ACC: proxy para conservadorismo contábil, medida baseada em accruals (GIVOLY; HAYN, 2000);

SROA: proxy para conflito (medida de incerteza operacional), desvio - padrão do ROA;

IND ON/PN: proxy para conflito, proporção do direito de voto (voting right) em relação ao direito a fluxo de caixa (cash flow right);

DIV: proxy para conflito, nível de dividendos distribuídos;

END: proxy para conflitos, nível de endividamento;

LOGATIVO: controle por tamanho, log do total de ativos;

REAV: controle por crescimento das vendas, retorno anual sobre as vendas.

dividendos, utilizando a proxy baseada em accruals para conservadorismo contábil (GIVOLY; HAYN, 2000).

Os resultados demonstram que há relação entre a incerteza operacional $\left(\beta_{2}\right)$ e o grau de conservadorismo, oferecendo indícios da relação entre conservadorismo contábil e os conflitos sobre políticas de dividendos verificados por meio desta proxy, corroborando os achados de Ahmed et al. (2002).

A relação é direta, em que dado um aumento da incerteza operacional resulta um aumento do conservadorismo contábil, indicado pelo sinal encontrado do coeficiente. Uma possível explicação para tal resultado é a de que firmas com maior incerteza operacional quanto a lucros futuros incorrem em um maior risco e, a partir dessa situação, os acionistas controladores podem requerer maior nível de conservadorismo contábil para evitar o pagamento de dividendos em excesso (AHMED et al., 2002; WATTS, 1993).
Utilizando a proxy para conflitos, medida pelo grau de concentração acionária $\left(\beta_{3}\right)$, essa não foi, estatisticamente, significante a nenhum nível de significância. Portanto, não há indícios de relação entre a variável concentração acionária e o conservadorismo contábil.

Ademais, foi possível apresentar evidências sobre a relação entre dividendos pagos $\left(\beta_{4}\right)$, grau de endividamento $\left(\beta_{5}\right)$ e conservadorismo contábil, porém com sinal distinto do esperado, sendo que se encontrou, em trabalhos anteriores, que maiores pagamentos de dividendos podem demandar maiores níveis de conservadorismo e firmas com maiores graus de endividamento acabariam por reduzir a distribuição de dividendos, o que poderia gerar conflitos sobre o seu estabelecimento (AHMED et al. 2002).

Com relação às variáveis de controle tamanho $\left(\beta_{6}\right)$ e crescimento das vendas $\left(\beta_{7}\right)$, os resultados mostraram-se, estatisticamente, significantes, confirmando a argumentação 
de que firmas maiores e com maiores oportunidades de ganhos podem realizar escolhas contábeis mais conservadoras, resultando em uma maior persistência de accruals negativos (AHMED et al., 2002; DECHOW; SLOAN, 1997; PENMAN; ZHANG, 1999; WATTS; ZIMMERMAN, 1978).

Por sua vez, a Tabela 20 apresenta os resultados para a mesma Equação 1 - A relação do conservadorismo contábil com conflitos sobre as políticas de dividendos, porém utilizando a proxy baseada no book-to-market para conservadorismo contábil (BEAVER; RYAN, 2000).

Os resultados indicam que utilizando a proxy para conservadorismo baseada no modelo de book-to-market de Beaver e Ryan (2000), não há relação entre conservadorismo contábil e os conflitos sobre políticas de dividendos, medindo-se pelas proxies incerteza operacional $\left(\beta_{2}\right)$, concentração acionária $\left(\beta_{3}\right)$ e dividendos pagos $\left(\beta_{4}\right)$.

Contudo, a proxy para conflitos sobre as políticas de dividendos medida pela variável endividamento foi, estatisticamente, significante, porém com sinal diferente do esperado, sugerindo que firmas com maiores graus de endividamento podem reduzir a distribuição de dividendos em função das obrigações adquiridas e comprometendo o desempenho futuro da firma, podendo gerar mais conflitos, semelhante aos resultados encontrados por Ahmed et al. (2002).

Com relação às variáveis de controle $\beta_{6}$ (tamanho) e $\beta_{7}$ (crescimento das vendas), somente a variável tamanho $\left(\beta_{6}\right)$ apresenta resultados estatisticamente significantes, o que pode indicar que, devido aos altos custos do conservadorismo, somente firmas maiores podem dispor de escolhas mais conservadoras (WATTS; ZIMMERMAN, 1978).

Em suma, os resultados encontrados indicam que existe relação entre o conservadorismo contábil e os conflitos sobre políticas de dividendos entre acionistas controladores e minoritários no Brasil, considerando-se a

Tabela 2 Estatística de Regressão em Painel - Efeito Fixo

Proxy para Conservadorismo Baseada em Book-to-Market $\times$ Conflitos $B T M=\beta_{1}+\beta_{2} S R O A_{i, t}+\beta_{3} I N D O N / P N_{i, t}+\beta_{4} D I V_{i, t}+\beta_{5} E N D_{i, t}+\beta_{6} L O G A T I V O_{i, t}+\beta_{7} R E A V_{i, t}+\varepsilon$

\begin{tabular}{l|c|c|c|c}
\hline BTM & Sinal Esperado & Coeficientes & Estatística $-\mathbf{t}$ & $\boldsymbol{P}$-value \\
\hline$\beta_{2}$ SROA & + & 1.110 & 1.55 & 0.122 \\
\hline$\beta_{3}$ IND ON/PN & + & 0.104 & 0.28 & 0.780 \\
\hline$\beta_{4}$ DIV & + & 0.003 & 0.96 & 0.335 \\
\hline$\beta_{5}$ END & + & -0.241 & -2.41 & $0.016^{* *}$ \\
\hline$\beta_{6}$ LOGATIVO & + & 0.196 & 2.02 & $0.043^{* *}$ \\
\hline$\beta_{7}$ REAV & + & 0.000 & 0.07 & 0.940 \\
\hline$\beta_{1}$ & -2.623 & -1.79 & 0.074 \\
\hline$R^{2}$ ajustado & & & & 0.1139 \\
\hline$N^{\circ}$ Observações & & & & 1007 \\
\hline Prob $>$ F & & & & 0.004 \\
\hline
\end{tabular}

em que: $*, * *, * * *$ Estatisticamente significantes ao nível de $1 \%, 5 \%$ e $10 \%$ respectivamente;

BTM: proxy para conservadorismo contábil, medida baseada no book-to-markets (BEAVER; RYAN, 2000);

SROA: proxy para conflito (medida de incerteza operacional), desvio - padrão do ROA;

IND ON/PN: proxy para conflito, proporção do direito de voto (voting rights) em relação ao direito a fluxo de caixa (cash flow rights); DIV: proxy para conflito, nível de dividendos distribuídos;

END: proxy para conflitos, nível de endividamento;

LOGATIVO: controle por tamanho, log do total de ativos;

REAV: controle por crescimento das vendas, retorno anual sobre as vendas. 
medida de conservadorismo baseada em $a c$ cruals. Já o mesmo não pode ser afirmado em relação à métrica relacionada ao patrimônio líquido.

\section{CONCLUSÕES}

O presente estudo buscou investigar, empiricamente, se há relação entre o conservadorismo contábil e os conflitos sobre as políticas de dividendos entre acionistas controladores e minoritários sobre as políticas de dividendos.

Foram utilizadas duas métricas para conservadorismo, uma baseada, exclusivamente, em variáveis contábeis (GIVOLY; HAYN, 2000) e outras com variáveis de mercado (BEAVER; RYAN, 2000).

Embora tenha sido encontrada relação estatisticamente significante entre conservadorismo e conflitos sobre as políticas de dividendos com algumas proxies utilizadas, os resultados encontrados não são conclusivos, uma vez que os resultados divergem entre as proxies para conservadorismo contábil. Tal fato, per si, é relevante para estudos futuros, pois os resultados variaram dependendo do tipo de métrica para avaliar o constructo "conservadorismo".

O conservadorismo medido com base em accruals apresentou relação estatisticamente significante com três métricas para conflitos: incerteza operacional, dividendos distribuídos e grau de endividamento. Esses resultados podem sugerir que firmas com conflitos podem demandar uma contabilidade mais conservadora, porém o mesmo não ocorreu com os resultados com base no book-to-market.

As conclusões encontradas devem ser analisadas dentro de seu contexto e apresentam limitações, tais como a existência de outros fatores que podem influenciar a relação do conservadorismo com conflitos sobre as políticas de dividendos e que não foram abordados e a não segregação dos dados por setores.

Em suma, as evidências encontradas oferecem indícios para a rejeição da hipótese testada $\left(\mathrm{H}_{0}\right)$, indicando que existe relação entre o conservadorismo contábil e os conflitos sobre as políticas de dividendos entre acionistas minoritários e controladores nas empresas brasileiras, porém os resultados divergem entre as diferentes medidas de conservadorismo. Contudo, os resultados encontrados em parte, corroboram a argumentação de que o conservadorismo possui função relevante dentro da estrutura contratual da firma.

\section{Referências}

AHMED, A. S. et al. The role of accounting conservatism in mitigating bondholder-shareholder conflicts over dividend policy and in reducing debt costs. The Accounting Review, v. 77, n. 4, p. 867-890, out. 2002. DUELLMAN, S. Accounting conservatism and board of director characteristics: an empirical analysis. Journal of Accounting and Economics, v. 43, n. 2-3, p. 1-27, July: 2007.

ALEN, F.; BERNARDO, A. E.; WELSH, I. A theory of dividends based on tax clienteles. The Journal of Finance, v. 55, n. 6, p. 2499-2536, 2000.

ANDERSON, C. W. Financial contracting under extreme uncertainty: an analyses of Brazilian corporate debentures. Journal of Financial Economics, v. 51, p. $45-84,1999$.

ANTUNES, G. A. Impacto da adesão aos niveis de governança da Bovespa na qualidade da informação contábil: uma investigação acerca da oportunidade, relevância e do conservadorismo contábil utilizando dados em painel. 2007. Dissertação (Mestrado em Contabilidade) - Programa de Pós-Graduação em Ciências Contábeis da Fucape, Vitória.

ASSAF NETO, A. Finanças corporativas e valor: São Paulo: Atlas, 2003.

BALL, R.; KOTHARI, S. P.; ROBIN, A. The effect of international institutional factors on properties 
of accounting earning. Journal of Accounting and Economics, v. 29, p. 1-51, 2000.

BASU, S. The conservatism principle and the asymmetric timeliness of earnings. Journal of Accounting and Economics, n. 24, p. 3-37, 1997.

BEAVER, W. H.; RYAN, S. G. Biases and lags in book value and their effects on the ability of the book-tomarket ratio to predict book return on equity. Journal of Accounting Research, v. 38, n. 1, p. 127-148, 2000. BEEKES, W.; BROWN, P. R.; CHIN, G. Do bettergoverned firms make more informative disclosures? Canadian evidence. Working Paper. 2007. Disponível em: $<$ http://papers.ssrn.com/>. Acesso em: 22 jan. 2008. BERLE, A.; MEANS, G. The modern corporation and private ownership. NY: MacMillan, 1932.

BLISS, J. H. Management through accounts. New York: Ronald Press, 1924.

CARVALHAL-DA-SILVA, A.; LEAL, R. Corporate governance index: firm valuation and performance in Brazil. Revista Brasileira de Finanças, v. 1, n. 3, p. 1-18, 2005.

COASE, R. H. The nature of the firm. Economica, London, v. 4, n. 16, p. 386-405, nov. 1937. COELHO, A. C. D. Qualidade informacional e conservadorismo nos resultados publicados no Brasil. 2007. Tese (Doutorado em Controladoria e Contabilidade) - Faculdade de Economia, Administração e Contabilidade, Universidade de São Paulo, São Paulo.

COSTA, F. M.; COSTA, A. C. O.; LOPES, A. B. Conservadorismo em cinco países da América do Sul. In: ENANPAD, Brasília, 2005.

DECHOW, P. M.; SLOAN, R. M. Returns to contrarian investment strategies: tests of naïve expectations hypotheses. Journal of Finance Economics, v. 43, n. 1 p. 3-27, 1997.

FELTHAM, G. A.; OHLSON, J. A. Valuation and clean surplus accounting for operating and financial activities. Contemporary Accounting Research, v. 11, p. 689-731, 1995.

GIVOLY, D; HAYN, C. The changing time-series properties of earnings, cash flows and accruals: has financial reporting become more conservative? Journal of Accounting and Economics, n. 29, p. 287-320, Ago. 2000.

GORDON, M. J. Optimal investment and financing policy. The Journal of Finance, v. 18, n. 2, p. 264-272, Maio 1963.

GUENTHER, D. A.; MAYDEW, E. L.; NUTTER, S. E.

Financial reporting, tax cost and book-tax conformity. Working Paper, 1997. Disponível em: <http://www.ssrn. com>. Acesso em: 13 dez. 2007.

JENSEN, M:; MECKLING, W. Theory of the firm: managerial behavior, agency costs and ownership structure. Journal of Financial Economics, v. 3, n. 4, p. 305-360, Out. 1976.

KELLOGG, R. L. Accounting activities, security prices, and class action lawsuits. Journal of Accounting \& Economics, p. 185-204, 1984.

KIM, B.; JUNG, K. The influence of tax costs on accounting conservatism. Working Paper. 2007.
Disponível em: <http://www.ssrn.com>. Acesso em: 23 jan. 2008.

LA PORTA, R. et al. Law and finance. The Journal of Political Economy, v. 106, n. 6, p. 1113-1155, 1998.

LA PORTA, R. et al. Agency problems and dividend policies around the word. The Journal of Finance, v. 55, n. 1, p. 1-33, 2000.

LEAL, R. P.; CARVALHAL DA SILVA; A. L.;

VALADARES, S. Estrutura de controle e propriedade das companhias brasileiras de capital aberto. Revista de Administração Contemporânea, v. 6, n. 1, p. 7-18, 2002. LIE. E. Excess funds and agency problems: an empirical study of incremental cash distrusements. The Review of Financial Studies, v. 13, n. 1 p. 219-247, 2000.

LINTNER, J. Dividends, earnings, leverage, stock prices and the supply of capital to corporations. The Review of Economics and Statistics, v. 44, n. 3, p. 243-269, Ago. 1962.

LOBO, G. J.; ZHOU, J. Did conservatism in financial reporting increase after the Sarbanes-Oxley act? initial evidence. Accounting Horizons, v. 20, n. 1, p. 57-73, 2006 LOPES, A. B.; MARTINS, E. Teoria da contabilidade: uma nova abordagem. São Paulo: Atlas, 2005.

LOPES, A. B.; WALKER, M. Firm-level incentives and the informativeness os accounting reports: an experiment in Brazil. Working Paper, 2008. Disponível em: <http://papers.ssrn.com>. Acesso em: 01 abr. 2008. LOSS, L.; NETO, A. S. Política de dividendos na prática, é importante? Revista Contabilidade \& Finanças, USP, São Paulo, Edição Comemorativa, p. 39-53, Out. 2003. LUBBERINK, M. J. P.; HUIJGEN, C. A wealth-based explanation for earnings conservatism. European Finance Review, n. 5, p. 323-349, 2000.

MARTINEZ, A. L. Gerenciamento dos resultados contábeis: estudo empírico das empresas abertas brasileiras. 2001. Tese [Doutorado em Ciências Contábeis] - Faculdade de Eçonomia e Administração e Contabilidade, Universidade de São Paulo, São Paulo. MODIGLIANI, F.; MILLER, M. Dividend policy, growth and the valuation of shares. Journal of Business, v. 34, n. 4, p. 411-433, out. 1961.

PENMAN, S. H.; ZHANG, X. Accounting conservatism, the quality of earnings, and stock returns. Working Paper. 2002. Disponível em: <http://www.ssrn.com>: Acesso em: 19 set. 2007.

POPE, P. F.; WALKER, M. International differences in the timeliness, conservatism, and classification of earnings. Journal of Accounting Research, v. 37, p. 53-87, 1999.

PROCIANOY, J. L. Conflitos de agência entre controladores e minoritários nas empresas brasileiras negociadas na bolsa de valores de São Paulo: evidências através do comportamento da política de dividendos após as modificações tributárias ocorridas entre 1988 1989. 1994. Tese [Doutorado em Ciências Contábeis] - Faculdade de Economia, Administração e Contabilidade, Universidade de São Paulo, São Paulo.

RANGEL, L. L. et al. O conservadorismo contábil e o valor de mercado. In: ENANPAD, 18., 2003, Atibaia. Anais... Atibaia, 2003. CD-ROM. 
ROYCHOWDHURY, S.; WATTS, R. L. Asymmetric timeliness of earnings, market-to-book and conservatism in financial reporting. Working Paper. Jan. 2007. Disponível em: <http://papers.ssrn.com/>. Acesso em: 06 jan. 2008.

SANTOS, L. S. R. Conservadorismo contábil e timeliness: evidências empíricas nos demonstrativos contábeis em US GAAP e BR GAAP das empresas com ADR'S negociadas na bolsa de Nova York. 2006. Dissertação [Mestrado em Ciências Contábeis] - Fundação Instituto Capixaba de Pesquisa em Contabilidade, Economia e Finanças, Vitória.

SARLO NETO, A. A reação dos preços das ações à divulgação dos resultados contábeis: evidências empíricas sobre a capacidade informacional da contabilidade no mercado acionário brasileiro. 2004. Dissertação [Mestrado Profissional em Ciências Contábeis] - Fundação Instituto Capixaba de Pesquisas em Contabilidade, Economia e Finanças, Vitória.

SILVEIRA, A. D. M. Governança corporativa e estrutura de propriedade: determinantes e relação com o desempenho das empresas no Brasil. 2004. Tese [Doutorado em Administração] - Faculdade de Economia, Administração e Contabilidade da Universidade de São Paulo, São Paullo.

SILVEIRA, A. D. M.; BARROS, L. A. B.; FAMA, R.
Estrutura de governança e desempenho financeiro nas companhias abertas brasileiras - um estudo empírico. In: SEMEAD, FEA USP, 6,. 2002. Disponível em: <http:// www.fea.usp.br/semead/6semead/finanças.htm $>$. Acesso em: 20 nov. 2007.

SMITH, C. W.; WATTS, R. L. Incentive and tax effects of executive compensation plans. Australian Journal of Management, v. 7, p. 139-157, 1982

WATTS, R. L. Corporate financial statements, a product of the market and political processes. Australian Journal of Management, v. 2, p.53-75, Apr. 1977. ; ZIMMERMAN, J. L. Towards a positive theory of the determination of accounting standards. The Accounting Review, n.1, v. 53, p. 112-134, 1978. A proposal for research on conservatism. Working paper, University of Rochester, 1993. Disponível em: <http://www.ssrn.com>. Acesso em: 12 nov. 2007. . Conservatism in accounting part I: explications and implications. Accounting Horizons, v. 17, n. 3, p. 207-221, Set. 2003a.

. Conservatism in accounting part II: evidence and research opportunities. Accounting Horizons, v. 17, n. 4, p. 287-301, Dez. 2003b.

ZEFF, S. A. Forging accounting principles in five countries: a history and analysis of trends 1971. Arthur Andersen Lectures Series, Champaign, IL: Stipes Publishing Company, 1972. 